\title{
SLANG EXPRESSION IN LITTLE MAN MOVIE BASED ON SOCIAL DIMENSION
}

\author{
Wiruma Titian Adi ${ }^{1}$ \& Alfian Azmi ${ }^{2}$ \\ ${ }^{1}$ Akademi Bahasa Asing BSI Jakarta \\ Jl. Salemba Tengah no. 45, Jakarta Pusat, Indonesia \\ Corresponding author: wiruma.wmt@bsi.ac.id
}

\section{${ }^{2}$ STIBA Nusa Mandiri \\ Jl. Damai no. 8, Margasatwa, Warung Jati Barat, Jakarta Selatan, Indonesia}

\begin{abstract}
This research aims to reveal the slang expression (slang words) uttered by some characters in Little Man movie. To analyze them, the writers use Holmes' references about social scale which is classified into four scales. By using qualitative descriptive method, the writers found 18 slang words then analyzed them into social distance scale, status scale, formality scale, or functional scale. After classifying these scales, it can be concluded that social distance scale is the mostly used in the movie. It can be assumed that social distance scale has told about the relationship between characters.
\end{abstract}

Key words: slang, social dimension, social scale, Little Man

DOI: 10.30957/lingua.v15i2.480.

\section{INTRODUCTION}

Almost all people in the entire world use English as their daily language to communicate with each other. That is the fact for hither yet cannot be denied and unavoided. A surely thing has been occurred that companies and large businesses will need to employ people who can speak more languages. That is where English comes in. It is now considered as an international language which almost people uses English.

There are many ways to learn English. One of the most favorite ways to learn English is watching movie. Movie or film is a sequence of photographs which is projected onto a screen with sufficient rapidity as to create the illusion of motion and continuity. Film maker do not create movies out of the blue, but they also there must have put intentions behind it. There areseveral themes contains within a movie; such as: humors, social, politic, love, education, and et cetera. Movie also is a modern literary work that has story fomation, dialogues, and also scenes which is performed by actor and actress to deliver these theme with purpose to entertain people. 
Movie also is like a result of human culture which is its existence has got its own place in the development of human civilization and history. Movie has two pointful purposes; providing an entertainment and also education. Through watching movie people absolutely will get entertainment as well as knowledge from the messages and values which is contained within the film. The people will be more open-minded and grow their imagination and expression about the life, love life, social, economic, politic, and etcetera. Through movies the film makes triy to deliver certain messages. Therefore, for the viewers should watch it deeply first to guess what the exact or essential message which is contained in it.

Movie can be assumed as the commemoration of someone's memories. It is like the writer is going to record his or her particular experience. There is also an intention of it. That is why the writer wants to raise the story and want to publish the story through the movie itself; in the hope that there is benefit that can be taken from it.

But sometimes, the viewers do not really understand a certain scene when they are watching a movie because of the language that is being used by the actor or actress of the movie. Despite of several times of repetitive or viewing watching the movie andagain, the result is will not as smooth as the viewers expect. Of the entire movie, there are a few scenes that probably make the viewers feel so confused, trying to understand what language is being used in the movie.

Thus, it can be known that every region has a different dialect. Dialect means a form of a language which seems peculiar or unusual for a specific region or social group. For instance, there are two people who come from different background are making a conversation. Both of them understand each other but only a few viewersunderstand their language.

In this case, mankind certainly cannot be separated from language use in their life. People need language to communicate with others. Language here is like a tool that connects one people to another. In communication process, language is needed to express the speaker's mind and feeling, so the listener can understand what the speaker means.

Within a group, for particular societies for instance, they may use variant of the language. They interact or communicate with each other by using a new word, but the fact here, they really accepted of that language which is being used and they speak as usual. For the same listeners, although they have the same tribe as the notabene, they might think that they will not quite understand of their new conversation.

Thus, the previous paragraphs discuss what slang is from the perspective of social dimension. Concerning a slang language, it is really correlated with the existence of linguistics. Then, linguistics is the study of human language. At first, linguistics was developed as a subject in the eighteenth century. Before then, language in the western world had been the interest largely of the philosophers. Futhermore, in the eighteenth century a number of scholars became interested in the relationship between European language and those of the Orient. Today linguistics is a science that concerns itself with all aspects relating to language, examining it from all of the theoretical viewpoints. 
Slang is one of the informal language varieties that emerge due to social factors that affect a group of people when they communicate. Slang appeared due to social background. Slang can be grouped as social dialect or sociolect in the branch of sociolinguistics. This Informal language variety typically used by lower middle-class people when they are communicating with their group. Since slang is a more specific and unusual than informal language, that caused not every member of society, even from the lower classes are able to abundantly know the meaning.

Based on the aforementioned statements, the writers would like to analyze the use of slang language and the comparison with the meaning base on English standard. Here, the writers are going to analyze it through a movie which entitled Little Man. Within this movie, both the male or the female characters use slang language many times.

Little Man is a 2006 American comedy film written, produced and directed by Keenen Ivory Wayans, and also written and produced by Wayans Brothers Marlon and Shawn Wayans, who also both starred in the lead roles. The film co-stars Kerry Washington, John Witherspoon, Tracy Morgan and Lochlyn Munro.The film was theatrically released in the United States on July 14, 2006 to commercial success but largely receive negative reviews, including three Golden Raspberry Awards.

The writers focus on two things related to slang language in the dialogues inLittle Man movie. First, the writers are going to list the slang expressions from the characters which are found inLittle Man movie. Second, the writersare going to find out what the meaning of the slang expressions are in Little Man. The writers useThe NTC's Dictionary of American Slang and Colloquial Expression, Dictionary of American Slang and www.yourdictionary.com to look for the meaning as a reference. Afterwards, the writers analyze the context in which the slang expression is appeared in this movie.

\section{THEORETICAL REVIEW}

\subsection{Sociolinguistics}

Language as a tool of communication has changed rapidly in society. A new word or term arises in few days or weeks. It is because language has a strong relation with social interaction which is a combination among a lot of factors such as a fast growing of communication technology, social media, and other factors. This dynamic changing oflanguage that used in society called sociolinguistic. Discussion about this reference is the same with talking about what happened in society. In this chapter we will discuss deeper about sociolinguistics.

Van Herk (2012) defines sociolinguistics is: "the scientific study of the relationship(s) between language and society" So, sociolinguistic has many connectivity between language and the people in particular groups. This means, a scientifically research that has a relationship between two matters here, there are the existence of language and the people. Both are really connected to each other.

In addition, Deckert \& Vickers (2011) state that "Sociolinguistics is a field that looks at how people use language in their everyday lives across a variety of life events 
and language experiences." Sociolinguistic is like a place where the people who use the language in their language experiences and it is the variety life events.

Based on the definitions above, sociolinguistics is like a large field who keep focus on two things, they are: language and society. Both of them are related each other also. On the other hand, Sociolinguistics aims at how people use language differently by their region and how individual speaker use language.

\subsection{Slang as Social Dialect}

Generally, slang is a subset of a language used by one particular group. It consists of words and expressions which will not be found in the dictionary, and can be distortions of existing words or entirely invented terms. It is used in informal situations. It is not appropriate in formal situations

Slang is an informal use of word in a language or in a specific group of people. This language is not considered as the speaker's language or dialect; however this kind of language is accepted in a certain social setting. Slang expression may act as a euphemism - a mild or less direct word substituted for one that is harsh or blunt when referring to something unpleasant or embarrassing- and may be used as a means of identifying with one peers.

Slang is the expression related or unrelated word or phrase is substituted for a more common one. The words that are replaced in slang are the most common ones: good (cherry, boss, phat, da bomb), bad (icky, yucky, jankety), crazy (nuts, bananas, crackers, bonkers), smart (brainy, savvy, sharp), fast (scream, tear out, fly, like greased lightning), slow (dragging, poky, crawling, creeping).

Here, certain people try to create slang language to communicate in their daily activity with one another. After they create it, they hope another group or people will not understand what they are talking about.

Slang is used by all kinds of groups of people who share situations or interests. The group which uses these words is always in the minority, and often uses slang to set themselves apart or make it difficult for ordinary people to understand them. When a particular new expression is known and used by a large majority of the population, it is no longer slang, but part of the regular language or usage.

When the conditions have changed, the term may have changed also in meaning, be adopted into the standard language, or continue to be used as slang within certain group of the population. It happened because their slang is known by another group and become popular for society. Thus, they cannot hide what they are talking or discussing about and they should change the slang in their group.

Slang is found in words not in grammar. When the people talk about slang, they intend to have a meaning, so the meaning means word, not a grammar or even pronunciation. This is more or less the correct view. Every language contains both a vocabulary and grammar. English is a language, but slang is not.

Relating to slang, slang is used for many purposes; but generally it expresses a certain emotional attitude; the same term may express absolutely opposed attitudes 
when used by different people. Many slang terms are primarily insulting, though they may also be ambivalent when used in intimacy or friendliness.

Slang also is not a swearing, because swearing is always connected with taboos of some kind, while slang terms are not limited in such way. Otherwise, it insults or shocks when it is used directly; some terms euphemize a sensitive concept, though clear or extreme euphemism may break the taboo more effectively than a less well-behaved term. Concerning slang, the writer has many explanations about slang from the experts.

Denham \& Lobeck (2014) state: "Slang words or phrases are typically very informal, and they are usually restricted to a particular group-typically teens and young adults-as a marker of in-group status." Slang can be categorized as an informal language; it cannot be spoken freely. It tends to only several targets, such as teen-ager and young adults.

Stolt (2010) states: “...slang has significant role: it is the tag that marks the belonging to a group and can serve to contracts friendship and to cement and maintain them." Hence, slang can be said as connector to be more friendship or to be accustomed to.

Overall, it can be concluded that slang is unconventional words or phrases that express either something new or something old in a new way. It is may be indecent or obscene. Slangemerges because of the needs of a group of people or community to express their solidarity among them by differentiate themselves in the way their talking. They create or modify the vocabulary of a language and use it as an identifying mark of their group or community and the use of slang itself need a deeper understanding about the relationship between the speaker and the recipient.

Concerning a slang language as a social dialect, generally therearemany factors that cause differences in the speaking style of a person at the time when communicating with each other. For the factor as the differences, such as: occupation, position, or duty of the speakers led to the emergence of the language variety. The language used by the labors, merchants, truck drivers, teachers, priests, or employer must be different. That because of the influence is based on their social environment and of what they do. Their language variety is mainly seen in areas of the vocabulary they use.

The existence of slang is related to a dialect. Dialect isa variety of a language that signals where a person comes from. The notion is usually interpreted geographically (regional dialect), but it also has some application in relation to a person's social background (class dialect) or occupation (occupational dialect).

Social dialect is a language variety which is dealing with several things, for instances: status, class and social class, age, education, sex, occupation, socioeconomic circumstances, etc. of the speakers. In sociolinguistics usually this kind of variety is the most widely discussed because of its relation to the personal issues of speakers.

Those statement is supported by (Wardaugh, 2006): "Social dialects originate among social groups and are related to a variety of factors, the principal ones apparently being social class, religion, and ethnicity." Social dialect affects many factors, for instance: social class, religion, and ethnicity. 
According to Siegel (2010) "Social dialect is a variety of a language spoken by a particular group based on social characteristic other than geography." In this universe, social dialect also includes to a variation of a spoken language which can be seen of the side of social characteristic.

From the whole describing above, it can be summarized that social dialect is a dialect that is concerning with the social status and class. The term social class that is related to the social dialect refers to the difference between people which are associated with differences in social prestige, wealth and education. People from different social do not speak in the same way. For example, teachers do not talk like farmers, laywer do not talk in the same way as the criminals they defend in court.

\subsection{Classification of Social Dimension}

Social dimension has function as indicator of the difference in social status between the speakers, also it can be an indicator of a situation in which language is used. In other words, social dimension is the reflection of purpose, topic, manner and mood of language used. Since this research also investigates the social function, it cannot be separated from the social dimension of communication. For instance, when a member in a particular community intends to express his or her feeling of anger toward the other member, he or she will consider the social dimension before uttering the feeling.

Holmes, Bell, \& Boyce (1991) state that there are four related social scales which then treats separately, those are: 1) a social distance scale, 2) a status scale, 3) a formality scale 4) functional scales.

\subsubsection{The Social Distance Scale}

Social distance may therefore be defined as a condition produced by a social relationship in conjunction with other social relationships. In other words, any specific social distance is a resultant of at least two relationships of differing tendencies, and inasmuch as a social relationship is after all only a relatively stable state of association or dissociation among human beings brought about and maintained by one or more social processes. It is impossible to define the latter in terms of distance: any social process is a sequence of occurrences through which the distance prevailing between human beingswill be either increased or decreased. The importance of distance as a sociological category thereby becomes apparent; it is the relatively stable equilibrium (of motions of approach and avoidance) produced by the dynamic interplay of social processes, and although the present system lays primary emphasis on social dynamics, it is a category of rank co-ordinate with social process.

Social distance scale is social dimensions taking account that will be a pattern of linguistic interaction. Social distance scale becomes an indicator of how well someone to know the other that will become a relevant factor in linguistic choices. Furthermore, in-group language is the language of solidarity. 
The function of in-group language becomes a variety that used to signal the shared identity of certain participants. Generally, it is used to show group difference, existence, or solidarity between the group members. The norms of language in a speech community are usually covered by-in group people. In-group language also conceals the use of certain language as the choices in the relation to social factor and social dimension of communication.

Social distance scale has an important function in emphasizing the intimacy of a relationship. How well and how close do people know someone, is a relevant factor in linguistic choice. The preference to call another's first name instead of their last name reflects their level of relationship towards intimate; therefore, it can be gathered that the level of solidarity is high. As oppose to the earlier example, a preference to call a stranger with just a Mr./Mrs./Ms. without an actual name attached to it, reflects just how distant their relationship is, resulting a very low solidarity level.

Here, the social distance between the persuader and persuadee (the one who is persuaded) should have an impact on their low degree of solidarity. However, the persuader knows what type of people he or she tries to persuade because he or she is aware of what type of social group is aimed at.

\subsubsection{The Social Status Scale}

Social class or status is one of the most important variables in social research. The socioeconomic position of a person affects his or her opportunities for several things, such as: educations, incomes, occupations, marriages, health, and friends, and it even can affect life expectancy. The variable has proved difficult to measure in a pluralistic, egalitarian, and fluid society. Many researchers nevertheless have tried to identify the social strata and to measure variables associated with them. Occupation has been shown to be the best single predictor of social status, and overall occupational prestige ratings have been found to be highly stable. A number of factors act in tandem in the relationship between occupation and social status. Both individual income and educational attainment are known to be correlated with occupational ranks. Education is a basis for entry into many occupations, and for most persons, income is derived from occupation.

Thus, the way people speak is influenced by linguistics variety account of dimension of social status. A member of community usually considered the person who will be addressed as a superior, a subordinate, or an equal when the member chooses a word to create various varieties. Therefore, the social scale status becomes consideration in some linguistics choices.

The process of persuasion can be initiated by a superior participant but also by a subordinate one. The persuader's social status determines the persuasive strategies he or she applies in the interaction. For instances: when a student persuades the teacher about his or her knowledge during the examination, their verbal contributions will reflect the examinee's lower and the examiner's higher social status. 
The status scale refers to status classification of the people involved in a conversation as an influence factor in linguistic preference. There are some considerations applied when a person is talking with someone from a higher level of class/occupation. It is applied when a secretary or a housekeeper greets their employer, for example they will greet him or her by "Good morning, Mr /Mrs. Budi" instead of "Good morning, John or Jane".

\subsubsection{The Formality Scale}

The formality scale is a useful tool to assess a social setting or a type of interaction in influencing a language choice. The use of language will be influenced by the formality of the setting. In a friendly chat held in cafes, people prefer to use a colloquial language. On the other hand, people tend to use formal language in a ritual service in church, or in a business transaction with a company manager. The degrees of formality are often determined by solidarity and status relationship, but not always. Despite personal relationship between speakers, a formal language will always be preferred in a very formal setting such as a law court.

Formality scale is a dimension influencing the variation of speech in different or context. The speakers will consider context and setting when they choosing a certain variety of linguistics choices. Here, there are many examples about formality scale is. They are: at law court and in the classroom.

This kind of scale is useful in assessing the influence of the social setting or type of interaction on languagechoice. A formal setting, such as a law court, will influence language choice regardless of thepersonal relationships between the speakers.

The formality scale also has essential part for speaker consideration on language choice based on social setting or type of interaction. For example when the students engage conversation with the lecturer in the classroom about sociolinguistics, the language used will be influenced by the formality of the setting.

\subsubsection{The Functional Scale}

Language form cannot be separated from the function of an interaction. The function scale dimension is formulated by referential and affective social meaning. The two factors formulating function scale dimension are particularly persuasive and basic. In addition, language can convey both objective information of a referential kinds and someone's feeling.

The sociolinguists aim at justifying the extent to which the function of a language or variety considerably shapes its use as any language or variety can convey objective information of a referential kind.

In general, the more referentially oriented an interaction is, the less it tends to express the feelings of the speaker. For instances, Radio broadcast of the weather forecast tend to put the emphasis on information or he referential function. By contrast, interactions which are more concerned with expressing feelings often have little in the way of new information to communicate. Talking between neighborsabout the weather, 
for instance, is more likely to be mainly affective in function, and intended to convey goodwill towards the neighbor rather than new information.

As the another example, the function scale that simultaneously operates referential function and conveys the speaker feels can be traced in television program such as the very familiar talk show, Oprah Winfrey Show. For instance, this TV program may provide a great deal of new referential information, while also clearly convey how the speaker feels about a certain topic.

From the several elaborations above, there are four steps of social dimension, they are: social distance scale, social status scale, formality scale and the last part is function scale. Each of depends on who the people are talking to,language choices convey information about the social relationships between people as well as about the topic of discussion and the last linguistic variation occurs at other levels of linguistic analysis: sounds, word-structure, grammar as well as vocabulary.

In the society, people may say the same thing in different way. It can be caused by context in which it is used. The choice of word in a conversation reflects factors such as the relationship between people in the particular situation and how the speaker feels about the person addressed. The difference way when a person says the same thing include linguistic variation such as: sounds, word structure, grammar, as well as vocabulary. The difference ways when we say thing is influenced by some social factors and dimensions. They are: a social distance scale concerned with participant relationships, a status scale concerned with participant relationships, a formality scale relating to the setting or type of interaction, two functional scales relating to the purposes or topic of interaction.

\section{METHOD}

In arranging this article, the researchers used library research only. The writers look for the needed theories from many sources to build the theoretical framework. To collect the data for the analysis the writers watch the Little Man movie, describe the social setting, make a list of slang expressions used by the characters and analyze the meaning by using a reference dictionary and the last is taking into account the situational context.

\section{FINDING AND DISCUSSION}

After watching the movie, the writers found some slang words/phrases discussed below. By finding the slang words, the writers then analyzed and classified it into social dimension.

Data1: 'Baby' (00.01.27)

Prisoner 1: He'll be back

Prisoner 2 : What's up, baby? 
The setting of the scene is at the jail. In this situation the officers tells Calvin that he will be free. When the officers accompany him to the lobby of the jail, there is one of the prisoners who does not like if Calvin get the freedom and they said a joke "he'll be back" and "what's up baby". The prisoner talks to the officer by using baby. From the general meaning of baby, it means "a very young child".

In this context, based on American Slang Dictionary, baby means cherished man. Thus, it is known that police officer has higher status that should be respected for.This case, based on the Social dimension aspect, the slang phrase belongs to "Social Status Scale". Occupation which has a role here are different status between prisoners and officers.

Data2: 'Hell' (00.01.57)

Calvin: Where the hell is this guy?

In this scene Calvin already got his freedom. He feels happy and so excited. When he goes out to the exit gate he feels disappoint that Percy does not come in time and he mention kind of expression "Where the hell is this guy?"

The expression above shows the disappointment meant to the people. Based on Standart English Dictionary, the meaning of hellis The place where some people are believed to go after death to be punished for ever for the bad things they have done during their lives. On the other hand, according to Kipfer \& Chapman (2007) in their dictionary, the word ofhell means for no definite or useful person, for fun. It only adds the variety of spoken language communication between Calvin and Percy (waiting for little man's friend). From this segment, the communication happens later between little man and his partner. They are so close; best friend. From the social dimension it belongs to "Social Distance Scale". Both have high solidarity each other.

Data3: 'POP' (00.02.15)

Calvin: What an idiot

Percy : Let me pop this door for my man

The segment here happens for two characters, Calvin and Percy. Calvinis going to get on the car and his partner replies by using pop. From the general meaning of pop, it is a kind of music. However from this context it is impossible to say variety of music. According to Spears (2000) in his dictionary means to hit or strike someone. The writers assume, the word pop means open (The door of the car). From the aspect of social dimension it belongs to "Social Distance Scale". Both characters have high solidarity to each other.

Data4: 'LOOT' (00.02.34)

Calvin : How much your man walken paying? 


\author{
Percy : Did this. A hundred G's \\ Calvin : A hundred G's? That's good loot
}

The conversation occurs between Cal and Percy. Cal says, "That's a good loot" to Percy. Stevenson (2011) stated thatloot means stolen money or valuable. However, the writers found the slang meaning of this word, that is lot. From the meaning of American Slang Dictionary, it is money, especially a large amount of money. So, it means showing much money. From the aspect of social dimension it belongs to "Social Distance Scale". Both have high solidarity to each other.

Data 5 : 'MESS, UP' (00.03.24)

Calvin: You better off stuffing your money in a mattress

Percy: Yeah. I bet you gonna mess your money up

The conversation happens between Cal and percy when Cal suggests Percy about the money, and Percy says "I bet you gonna mess yor money up". Based on American Slang Dictionary, "mess, up" means to put someone or something into disorder. So, in this conversation the writersanalyzed that Percy believe that Cal cannot save his money; he will mess up the money. From the aspect of social dimension it belongs to "Social Distance Scale" because they are close friendwith high solidarity to each other.

Data6: 'HOMEBOY' (00.04.13)

Musician : You done stepped up to the plate. Give a hug, homeboy

The conversation begins between Darryl and Musician. Darryl gives an instruction to the Musician that today is the biggest day for Darryl to his wife (Vanessa). Some of the Darryl's instruction can be understood completely by the musician.From the explanation of Standard Cambridge english Dictionary, homeboy means "a boy or man from your own town, or someone who is a close friend". Based on American slang Dictionary the writers found the meaning of homeboy is "A person from one's hometown.

The researchers conclude that it has the similar meaning but it has different interpretation. The conversation happens in a restaurant and they are while making the conversation is like close friend each other. So, the social dimension reflected here refers to "Social Status Scale" where Darryl and a Musician are different status between musician and the guest in the restaurant.

Data7 : 'COOL' (00.06.58)

Calvin: Hey, I'm willing to do whatever it takes

Vanessa: So, no more late-night poker with the guys

Calvin : Cool 
Vanessa and Darryl met at the restaurant. They have made an appoinment before, but Darryl came earlier then he waits for a few minutes. When they met each other, they straight to the topic of conversation. Darryl talks about wants to make a plan of their future life with Vanessa, but Vanessa doesn't interested with Darryl's plan about having baby.

In part of their conversation, it contains of slang language cool. Based on the standart English cambridge dictionary cool is adjective word that means "describe a temperature that is slightly too cold". Based on www.yourdictionary.com cool also slang word which have the meaning "very good, pleasing, and excellent".

The scene shows that the characters between Vanessa and Darryl is very close each other because they are couple.So, based on social dimension "cool" at this conversation can be categorized into "Social distance Scale".

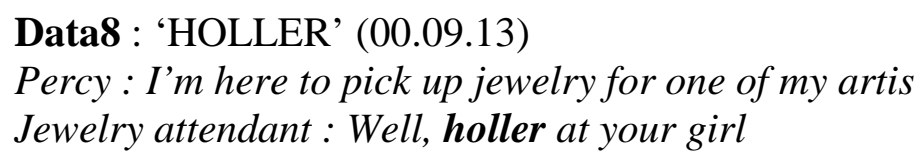

Percy pretends to be CEO and A\&R of P-Units Records to pick up jewelry for one of his artist. He and Calvin came to jewelry shop to steal the big diamond inside the quarter glasses box. Percy tried to distract the jewelry attendant and Calvin do his action to steal the diamond.

In this scene, Percy and jewelry attendant make the conversation each other and there is one of the conversation jewelry attendant said "Well, holler at your girl". Based on the standard English language holler means "to shout or call loudly". This is kind of informal language or it can be called by slang language that hollerhas a meaning "A Souther black folk song with spoken or shouted words, a precursor of the blue song"based on the American Slang Dictionary.

Social Dimension that occurs in this conversation between Percy and jewelry attendant as" formality scale" where they are having interaction session inside of the room which refers to a formal situation when jewelry attendant offers for help to Percy and it occurs view of informal conversation.

\section{Data9 : 'BOUNCE' (00.10.26) \\ Percy : Let me get up out of here. I gotta bounce}

This conversation is between Percy and jewelry attendant. Here occurs when Percy already known that Calvin succesfuly gets the diamond, Percy talks to jewelry attendant like he wants to come out from the jewelry shop immediately. In the middle of the conversation Percy said "Let me get up out of here. I gotta bounce".

In this conversation, the writers know that the general meaning ofbounce is "To move up or away after hitting a surface, or to cause something to move this way". But, this word "BOUNCE" also can be categorized in slang language which means "In (for 
a heck) to returned from the bank because of insufficient funds" based on American slang and Colloquial Dictionary".

Here in this scene contains of the Social Dimension that occurs in this conversation between Percy and jewelry attendant as the formality scale where they still having interaction session inside of the room which refers to formal situation that Percy tells to jewelry attendant that he wants to go out immediately.

Data10 : 'CRAP' (00.10.54)

Jewelry attendant : Holly crap!! The Queen's diamond its gone

This scene occurs when the jewelry attendant realizes that the diamond has been stolen. She get surprised that the diamond is missing. She assumed the man who stole the diamond is the guy who was talking with her (Percy). In this part, she said something kind of expression holy crap, it is one of the expression using slang words.

Based on Cambridge English Dictionary craphas meaning "Solid waste, or an occasion when an animal or person produce solid waste" It is also part of noun phrase. But "CRAP" based on American Slang and Colloquial Dictionary has a meaning "Dung (often used as a milder replacement for shit)".

However, this expression has negative meaning, because she said impolite word. The Social dimension that occurs in conversation is a status where between the jewelry attendant and security officer are superior and subordinate. So, the slang expression which consits in that conversation is The Social Status Scale.

$$
\begin{aligned}
& \text { Data11 : 'MUTT' (00.11.13) } \\
& \text { Calvin: Get out of here, mutt } \\
& \text { Percy : You just tossed Chihuahua }
\end{aligned}
$$

This scene occurs where Calvin and Percy tried to escape with their car. But there is a dog who distract them in his bag. Calvin and Percy got panic because the dog make a noise. Then Calvin threw off the dog by saying "Get out of here, Mutt". In this part Calvin really does not like the dog and expressing kind of slang expression mutt

Based on the Standart English Cambridge Dictionarymutthas a meaning "dog that does not have a predigree". But in this slang expression based on www.yourdictionary.commutthas a meaning "a dog of mixed breed; mongrel".

However this is a negative expression in slang word that occurs between Calvin and the dog. The Social Dimension that contains of the dialogue belongs to The Social status Scale because they are totally different as a living nature.

Data12 : 'BEJESUS' (00.12.25)

Calvin: What? You shot?

Percy : Sweet bejesus. My muscle, I think I pulled 
Calvin and Percy try to escape from the police. They got panic and they do not know what they are going to do until they left their car in the street. While their escape, Percy feels something wrong in his back. Normaly when someone get pain suddenly usually they mention "oh my god, oouuh..., or oh my lord. It also used to express surprise, pleasure, anger, annoyance, etc. But, this scene occurs when Percy had a pain with his back he said the words which can be categorized into slang expression. Here he said "Sweet Bejesus", as we know it word is informal language that only particular group of the people known each other.

Based on www.yourdictionary.combejesus has meaning is "a term of indefinite meaning, often used to provide emphasis, esp. This scene shows that the character between Percy and Calvin have close relationship. The Social dimensions that take place in this conversation as "The Social Distance Scale". The slang expression appears here they feel intimacy and solidarity each other.

\title{
Data13 : 'DITCH' (00.14.14) \\ Percy: You still got the diamond? \\ Calvin : No, I had to ditch it
}

The conversation happens when Percy asksthe diamond to Calvin, but Calvin put the diamond into someone's bag. Luckly, the bag belongs to Vanessa because Calvin did not have any idea where he should hide the diamond. Finally the conversation occured between Percy and Calvin.

Slang expression that Calvin said is "I had to ditch it". The writers can analyze there is word which contain slang word. Ditch based on Cambride Dictionary has general meaning "a long, narrow, open channel dug in the ground, usually at the side of a road or field". But based on slang dictionary in www.yourdictionary.com, ditch is "to get rid of".

The way of the slang expression that Calvin says to Percy can be categorized to an informal language. It occurs because they have close relationship and the social dimension which contain in this scene belongs to "The social Distance Scale"

\author{
Data14 : 'BUM' (00.15.52) \\ Pops : So, what the good news? \\ Vanessa: Dad.. I got the promotion \\ Pops : Congratulations. Soon you'll make enough money to leave that bum
}

The situation began when Darryl and Vanessa arrived at their home then they met Pops (Vanessa's dad). The conversation occurs between them, Vanessa is very excited to tell the good news to Pops that she get promotion in her office. Pops gives his respond to Vanessa with saying "soon you'll make enough money to leave that bum". 
The sentence aboves is impolite expression to be mentioned. Because Pops mention it to someone. There is slang word can be analyzed it is bum has general meaning " a person who gets money by asking other people for it". That definition is taken from Cambridge English Dictionary. Based on www.yourdictionary.combumhas slang meaning is "To upset, distress, annoy, depress, bore to someone".

The character here that Pops mention an expression to Darryl shows that Pops does not like Darryl very much. This scene shows conversational context between Pops (father in law) and Darryl (son in law) in "The Formality Scale" in informal situation.

Data 15: 'CRACKHEAD' (00.22.39)

Darryl : Beside his birth parents are probably crackhead.

At this scene, Vanessa and Darryl brought Calvin (Little man) to see the doctor. They just make sure that Little man is in a good body, good temperature and healthy. While they are checking Little man's body to the doctor they are wondering what kind of this Little man looks like. Because this Little man looks like horrible such as has scar at his body, and kind of tattoos like a man. This situation occurs between Darryl and Vanessa where there is part of conversation which containing slang word. From the explanation, there is no meaning related to the slang word crackhead. But, from the explanation of American Slang and Colloquial Dictioanry, crackheadcan be categorized as slang word which means "a user of crack (drugs)".

The character here between Vanessa and Darryl use informal language. Due to they have a very high intimacy, the Social Dimension reflected here refers to "Social Distance Scale" where the conversation between them as a couple is very close each other.

Data 16: 'JEEZ' (00.25.O6)

Pops : Jeez, man, you can't be popping up like that.

At this scene, when Pops is wacthing movie with eating some cookies, he is really surprised when he saw Cal (Little man) suddenly appears in his face. In this situation Pops express the word which containing slang word. He feels scare and surprised and also irritated with Cal (Little man).

Jeez is one of slang word which can be found at this dialogue. There is no explanation about the meaning of this word in standard english. Based on American Slang Dictionary, jeez is includedinto interjection, and it has a meaning "An exclamation of surprise, dismay, emphasis, etc".

From the explanation above, Pops uses an interjection in his dialogue. $\mathrm{He}$ mentioned to Cal (Little man)with an expression. So, the Social Dimension that occurs in this dialogue is show the status between Pops and Calvin (Little man) are different status and it can be categorized as "The Status Social Scale" where they don't have blood sibling each other. 
Data 17: 'FELLA' (00.41.42)

Darryl : Hey, when did he get in the bed?

Vanessa: I don't know how he gets out of the crib. He such a crafty littleFella

The conversation occurs between Darryl and Vanessa in the morning and they are talking about their experience when on the bed last night. Vanessa fells wonderful to Darryl because Darryl did greatful last nite. But, Vanessa is surprised and wondering when Calvin(Little man) get in her bed last night?? She didn't expect that Calvin(Little man) like a crafty little baby.

From the conversation above, there is a sentence which contains of slang word is fella, can be identificated easly that it word is slang. From the explanation of American Slang and Colloquial Dictionary, fellahas meaning is 'fellow of the guy'. It is used in any of particular group.

This scene shows that the characters between Darryl and Vanessa are close each other. There is intimacy between them as husband and wife and the Social Dimension of slang word can be categorized as " The Social Distance Scale" because they expresses their intimacy each other.

Data 18: 'SUCK' (01.07.07)

Son : Dad.. dad..

Dad : Yeah, son?

Son : You suck !!

In this scene, there is a conversation between son and his daddy. They are playing football as a team, but their team get lose because of his daddy makes mistake in the game. The son is reacted he feels anger and upset to his dad. When the son approached his dad he mentioned the word suck.

Based on standard english from Cambridge dictionary, suck has meaning 'To pull in liquid or air through your mouth without using your teeth, or to move the tongue and muscles of the mout arround something inside your mouth'. Based on www.yourdictionary.com suck has slang meaning, it is "to be contemtible or very unsatisfying or as because of low quality".

However, it is kind of negative expression. A son should not mention to older people using kind of that words. This conversation occurs between son and daddy where they have deep relationship each other. Therefore, it can be categorized from Social Dimension as "The Social Formality Scale" which is the slang expression to express the solidarity between them and they have conversation inside of the football game which is informal situation.

\section{CONCLUSION}

Using slang word/phrase can be applied in different social scale, they are social status scale, social distance scale, social formality scale, and social function scale. All 
scales stated by Holmes et.al have been elaborated by using slang words/phrases as examples of applying them in conversation in Little Man movie. Those kinds of socials status are really related to the use of slang language. Based on conversation in the movie, the writers revealed 18 data/slang words and the characters in the movie mostly used slang words in social distance scale.

The writers have analyzed the meaning of slang within the movie and hope that this analysis can be useful for the readers to apply some slang words in their conversation.

\section{REFERENCES}

Deckert, S. K., \& Vickers, C. H. (2011). An Introduction to Sociolinguistics : Society and Identity. California: A\&C Black.

Denham, K. E., \& Lobeck, A. C. (2014). Linguistics at School : Language Awareness in Primary and Secondary Education. London: Cambridge University Press.

Holmes, J., Bell, A., \& Boyce, M. (Mary T. (1991). Variation and Change in New Zealand English : a Social Dialect Investigation. Melbourne: Dept. of Linguistics, Victoria University.

Kipfer, B. A., \& Chapman, R. L. (2007). Dictionary of American Slang. New York: HarperCollins Publishers.

Siegel, J. (2010). Second Dialect Acquisition. Cambridge: Cambridge University Press.

Spears, R. A. (2000). NTC's Dictionary of American Slang and Colloquial Expressions. New York: NTC Publishing Group.

Stevenson, A. (2011). Oxford Dictionary of English. London: Oxford University Press.

Stolt, R. (2010). The Translation of Slang: Within the Bounds of Possibility? Munich: GRIN Publishing.

Van Herk, G. (2012). What is Sociolinguistics? Canada: Wiley-Blackwell.

Wardaugh, R. (2006). An Introduction to Sociolinguistics. Malden: Blackwell Publishing. 